\title{
Mental health outcomes of widowed and married mothers after war
}

\author{
Nexhmedin Morina and Paul M. G. Emmelkamp
}

\section{Summary}

We assessed prevalence rates of mental disorders in 206 mothers who had experienced the Kosovo war 10 years previously: 100 lone mothers widowed by the war, 71 nonbereaved married mothers, and 35 married mothers bereaved since the war (loss of family other than husband). A total of $96 \%$ of widowed lone mothers reported a major depressive episode, an anxiety disorder or a substance use disorder as compared with $54.9 \%$ and $60 \%$ in the married groups. Furthermore, $45 \%$ of widowed lone mothers reported current suicide risk as compared with $16.9 \%$ and $22.9 \%$ in the married samples. War-related widowhood combined with lone motherhood constitutes a significant factor for elevated psychopathology

\section{Declaration of interest}

None.
Exposure to war-related traumatic experiences among civilians is associated with elevated prevalence rates of major depressive episode and post-traumatic stress disorder (PTSD). ${ }^{1}$ Yet, warrelated experiences can comprise a broad variety of events and the very nature of certain events has received little scientific attention. Results from research on violent death of significant others $^{2-4}$ and from bereavement in general ${ }^{5-7}$ suggest that warrelated bereavement might constitute a significant risk factor for psychopathology above and beyond other war-related events. However, research on war-related bereavement has been very scarce and inconclusive given the limitations either related to not differentiating between deceased family members and friends ${ }^{8}$ or to very small samples. ${ }^{9,10}$ We investigated the incidence of mental disorders among a bereaved group of war survivors that has been reported to have high levels of psychopathology: ${ }^{9}$ widowed lone mothers who have experienced the war as civilians, have additionally lost their husband during war and have been lone mothers since. Further, we compared these findings with those in non-widowed mothers.

\section{Method}

Interviews were conducted face to face in 2009 in the region of Drenica in Kosovo, where about $6.5 \%$ of the total Kosovar population live. All participants had experienced at least one war-related traumatic event during the Kosovo war in 1998/ 1999. Interviews were conducted by five female psychologists who had been trained in administering the Mini International Neuropsychiatric Interview $(\mathrm{MINI})^{11,12}$ for a prior project. ${ }^{13}$ The interrater reliability for the MINI in the prior project demonstrated good kappa scores (0.92-0.94). The ethics committee of the University of Amsterdam approved the study.

Lists of families with war-related loss in the region of Drenica were provided by communal authorities. The wives of the first 146 deceased husbands from the list were contacted, of whom 28 reported not having children. Of the 118 potential participants, 14 widowed mothers refused to participate in the study $(88.1 \%$ participation rate). Four participants were excluded because of missing data. All 100 participants had been lone mothers ever since, as it is the accepted custom in Kosovar society that a widowed mother should not remarry.

A random-walk approach that involved random identification of streets in exactly the same localities where bereaved mothers were contacted was used to recruit non-bereaved mothers. ${ }^{13}$ On a particular street, every third house on the right was approached, with a maximum of 15 interviews for that street. Of 195 households contacted, 74 did not have children. Of the remaining 121,12 declined to participate ( $90.1 \%$ participation rate). Three participants were excluded because of missing values. Thirty-five mothers reported natural death of parents or siblings after the war. Consequently, married mothers were divided into two groups: 71 non-bereaved married mothers who did not report loss of family members during or after the war and 35 bereaved married mothers who reported loss of family members (other than the husband) after the war.

Traumatic events were measured using a checklist assessing 18 war-related events. ${ }^{14}$ Current major depressive anxiety, anxiety disorders, suicide risk and substance use disorders were assessed with the MINI. ${ }^{11,12}$ Prolonged grief disorder was assessed with the Prolonged Grief Disorder Interview, ${ }^{6,9}$ which is a structured diagnostic interview.

\section{Results}

Widowed lone mothers were significantly older (mean 50.1 years (s.d.=7.9)) than both non-bereaved (mean 47.3 (s.d.=6.4), $t(169)=2.58, P=0.01$ ) and bereaved married mothers (mean 46.3 (s.d. $=5.8), t(133)=2.71, P<0.001)$. Further, they reported a lower monthly income (mean $€ 232.2$ (s.d. $=163.3$ )) than nonbereaved married mothers (mean €331.7 (s.d.=233.5), $t(169)=-3.27, P=0.001)$ ) and fewer years of education (mean 6.1 (s.d. =3.5)) than bereaved married mothers (mean 7.5 (s.d.=4.1), $t(133)=-2.20, P=0.03)$. Widowed lone mothers reported a higher number of war-related traumatic events (mean 30.7 (s.d. =16.14)) than non-bereaved married mothers (mean 23.0 (s.d. $=18.85), t(169)=2.25, P=0.03)$, but not than bereaved married mothers (mean $26.6($ s.d. $=18.6)$ ).

Among widowed mothers, $96 \%$ met criteria for major depressive disorder, an anxiety disorder or a substance use disorder, compared with $54.9 \%$ of non-bereaved and $60 \%$ of bereaved married mothers. None of the married mothers and only six widows met criteria for substance use disorders (dependence on sedatives). Widowed lone mothers reported higher prevalence rates of major depressive disorder (71\%), PTSD (82\%), generalised anxiety disorder $(48 \%)$ and suicide risk $(45 \%)$ than non-bereaved (18.3\%, 29.6\%, 9.9\% and $16.9 \%$, respectively) and bereaved married mothers $(25.7 \%, 25.7 \%, 25,7 \%$ and $22.9 \%$, respectively), all $P \leqslant 0.05$. Among widowed lone mothers, $69 \%$ suffered from 
prolonged grief disorder. Rates for meeting criteria for PTSD or major depressive episode but not for prolonged grief disorder were $28.0 \%$ and $21.1 \%$, respectively.

Sociodemographic, war-related and loss-related variables that differed significantly between groups were included in multivariate logistic regression analyses. Torture was included in the analyses in addition to number of war-related traumatic events as it has been reported as a significant predictor of psychopathology. ${ }^{15}$ Finally, group status (widowed lone mothers $v$. comparison groups) was entered in the analyses. All variables were entered simultaneously. Widowed lone mothers maintained higher rates of major depressive episode and PTSD than both married groups (all $P \leqslant 0.01$ ). Furthermore, they maintained significantly higher rates of generalised anxiety disorder and suicide risk than non-bereaved married mothers (all $P \leqslant 0.01$; online Table DS1).

\section{Discussion}

A decade after war, widowed lone mothers reported very high rates of major depressive episode, anxiety disorders, prolonged grief disorder and current suicide risk. These rates remained significantly higher among widowed lone mothers than among non-bereaved married mothers even after controlling for sociodemographic and trauma characteristics. Generalisation of the findings is limited because of the relatively small sample sizes and recruitment of participants in only one region. Underreporting of sexual abuse and substance use disorders might have occurred, as these may be perceived as unacceptable in the mostly Muslim Kosovar society. No power analysis was conducted prior to the study and some of the analyses might be underpowered. Findings might still be subject to unobserved confounding by war-related and post-war factors. Groups were recruited in different ways, which might have led to higher rates of mental disorders among widowed mothers than among mothers recruited using random sampling. To enhance participation rate, potential participants were contacted at home and thus the interviewers were not masked. However, given that psychopathology was assessed with a structured interview by trained professionals it is unlikely that potential observer bias accounts for the large differences among groups.

Our results indicate that war-related widowhood when paired with lone motherhood is associated with higher prevalence of depression, anxiety disorders and suicide risk than revealed by the general post-conflict literature. ${ }^{1,13}$ Emotional, functional and economic difficulties might influence psychopathology among widowed lone mothers. This population must cope with their own experiences of war, loss of the husband (which meant also loss of the main breadwinner) and raising children on their own. The accepted norm in Kosovar society that a widowed mother should not remarry, resulting in forced lone motherhood, is likely to negatively affect coping mechanisms and to hamper attempts at mastering socioeconomic circumstances. Thus, lone motherhood is likely to constitute a significant factor in the elevated prevalence rates of mental disorders. ${ }^{16-18}$ Further factors that might influence mental health in this population are ongoing societal and political instability and unsatisfactory health and social care. Future research needs to address the extent to which lone parenthood is independently associated with psychopathology. The high mental morbidity rates among war-related widowed lone mothers call for long-term policies to meet their special mental health needs. Kosovar society as a whole should reconsider the cultural attitude that widowed mothers should not remarry.
Nexhmedin Morina, PhD, Paul M. G. Emmelkamp, PhD, University of Amsterdam Department of Clinical Psychology, Amsterdam, The Netherlands

Correspondence: Nexhmedin Morina, PhD, University of Amsterdam, Department of Clinical Psychology, Roetersstraat 15, 1018 WB Amsterdam, The Netherlands. Email: (n.morina@uva.nl)

First received 24 Feb 2011, final revision 20 Jul 2011, accepted 28 Jul 2011

\section{Funding}

This study was in part funded by a grant from the Royal Netherlands Academy of Arts and sciences and in part by a grant from the Children and War Foundation.

\section{References}

1 Steel Z, Chey T, Silove D, Marnane C, Bryant RA, van Ommeren M. Association of torture and other potentially traumatic events with mental health outcomes among populations exposed to mass conflict and displacement: a systematic review and meta-analysis. JAMA 2009; 302: 537-49.

2 Stroebe M, Schut H, Stroebe W. Health outcomes of bereavement. Lancet 2007; 370: 1960-73

3 Kaltman S, Bonanno GA. Trauma and bereavement: examining the impact of sudden and violent deaths. Anxiety Disord 2003; 17: 131-47.

4 Murphy SA, Lohan J, Braun T, Johnson LC, Cain KC, Beaton RD, et al. Parents health, health care utilization, and health behaviors following the violent deaths of their 12- to 28 -year-old children: a prospective longitudinal analysis. Death Stud 1999; 23: 589-616.

5 Prigerson HG, Frank E, Kasl SV, Reynolds CF, Anderson B, Zubenko GS, et al. Complicated grief and bereavement-related depression as distinct disorders: preliminary empirical validation in elderly bereaved spouses. Am J Psychiatry 1995; 152: 22-30

6 Prigerson HG, Horowitz MJ, Jacobs SC, Parkes CM, Aslan M, Goodkin K, et al. Prolonged grief disorder: psychometric validation of criteria proposed for DSM-V and ICD-11. PLoS Med 2009; 6: e1000121.

7 Bonanno GA, Neria Y, Mancini A, Coifman KG, Litz B, Insel B. Is there more to complicated grief than depression and posttraumatic stress disorder? A test of incremental validity. J Abnorm Psychol 2007; 116: 342-51.

8 Momartin S, Silove D, Manicavasagar V, Steel Z. Complicated grief in Bosnian refugees: associations with posttraumatic stress disorder and depression. Compr Psychiatry 2004; 45: 475-82.

9 Morina N, Rudari V, Bleichhardt G, Prigerson HG. Prolonged grief disorder, depression, and post-traumatic stress disorder among bereaved Kosovar civilian war survivors. A preliminary investigation. Int J Soc Psychiatry 2010; 56: $288-97$

10 Schaal S, Elbert T, Neuner F. Prolonged grief disorder and depression in widows due to the Rwandan genocide. Omega 2009; 59: 203-19.

11 Sheehan DV, Lecrubier $\mathrm{Y}$, Sheehan $\mathrm{KH}$, Amorim $\mathrm{P}$, Janavs J, Weiller $\mathrm{E}$, et al. The Mini International Neuropsychiatric Interview (M.I.N.I.): the development and validation of a structured diagnostic psychiatric interview. J Clin Psychiatry 1998; 59: 22-33

12 Morina N. Versioni shqip i Mini International Neuropsychiatric Interview [Albanian version]. Zana, 2006

13 Priebe S, Bogic M, Ajdukovic D, Franciskovic T, Galeazzi GM, Kucukalic A, et al. Mental disorders following war in the Balkans - a study in five countries. Arch Gen Psychiatry 2010; 67: 518-28.

14 Morina N, von Lersner U, Prigerson HG. War and bereavement: consequences for mental and physical distress. PLOS One 2011; 6: e22140.

15 Basoglu M, Paker M, Ozmen E, Tasdemir O, Sahin D. Factors related to long-term traumatic stress responses in survivors of torture in Turkey. JAMA 1994; 272: 357-63.

16 Franz $\mathrm{M}$, Lensche $\mathrm{H}$, Schmitz $\mathrm{N}$. Psychological distress and socioeconomic status in single mothers and their children in a German city. Soc Psychiatry Psychiatr Epidemiol 2003; 38: 59-68.

17 Loxton D, Mooney R, Young AF. The psychological health of sole mothers in Australia. Med J Aust 2006; 184: 265-8.

18 Ringbäck Weitoft G, Haglund B, Rosén M. Mortality among lone mothers in Sweden: a population study. Lancet 2000; 355: 1215-9. 